\title{
Morphometric Analysis of The Mandibular Incisive Canal in Different Facial Patterns
}

\author{
Eduardo dos Santos Filho, Renata Dantas Barreto, and Rudyard dos Santos Oliveira
}

\section{ABSTRACT}

\begin{abstract}
The study evaluated the morphometry of the mandibular incisive canal correlating with the different patterns of facial growth. The sample consisted of 90 cone beam computed tomography scans, divided into 3 groups: brachyfacial $(n=30)$, mesofacial $(n=30)$ and dolicofacial $(n=30)$. For the determination of these groups, the acquisitions were arranged in the Dolphin 3D software to perform the Ricketts 3D cephalometric tracing and the VERT index. Next, the images were worked on the Ondemand3d software to perform the morphometric analysis of the incisive canal. For data analysis, the Kruskal-Wallis and Mann Whitney test were performed to test the interference of facial patterns, sex and age in the Mandibular Incisive Canal Extension. In the intragroup analysis of the MICE, the Friedman test was used, considering a $95 \%$ confidence interval and a significance level of $5 \%$. The sample consisted of $54.4 \%$ of males and $45.6 \%$ of females. Sex and age had no effect on morphology and incisive canal extension. When the relationship between facial patterns and MICE was observed, brachyfacials $(11.09 \mathrm{~mm})$ presented a larger extent $(p<0.001)$ than dolicofacial $(4.10 \mathrm{~mm})$ and mesofacial $(5.55 \mathrm{~mm})$. When the morphology of the MIC was analyzed, most individuals presented the linear horizontal format, and there was no direction between the groups. Thus, we can conclude that the facial pattern influences the MICE and sex, age and morphology were not influenced by the facial pattern.
\end{abstract}

Keywords: Tomography. Cephalometry. Forame Mentual.
Published Online: October 30, 2020

ISSN: $2684-4443$

DOI : $10.24018 /$ ejdent.2020.1.5.24

\section{Eduardo dos Santos Filho}

Dentistry Department, Uninassau College, João Pessoa, PB, Brazil.

(email: eduardosantosfilho11@ gmail.com) Renata Dantas Barreto

Dentistry Department, Uninassau College, João Pessoa, PB, Brazil.

(email: renatadantasbarreto@gmail.com) Rudyard dos Santos Oliveira *

Dentistry Department, São Leopoldo Mandic College, Campinas, SP, Brazil.

(e-mail: dr.rudyardoliveira ${ }^{\circledR}$ gmail.com))

\section{INTRODUCTION}

Some dental surgeries involve noble structures or areas adjacent to them, such as the mandibular canal, and these require an accurate knowledge of the anatomical form of this structure to avoid injury to the inferior alveolar nerve present in the canal.[1], [2].

The planning of implant treatment should be judicious, as the length, diameter and angulation of the implants are crucial factors to the success of each case. The shape and height of the alveolar bone as well as noble structures such as the mandibular canal and floor of the maxillary sinus should be precisely localized and carefully considered prior to treatment with implants. It is essential an adequate clinical examination and complementary survey of images [3]-[5].

Some dental surgeries involve noble structures or areas adjacent to them, such as the mandibular canal, and these require an accurate knowledge of the anatomical form of this structure to avoid injury to the inferior alveolar nerve present in the canal [6], [7].

The mandibular incisive canal (MIC) usually begins from mesial to the projection of the mental forame and advances from posterior to anterior parallel to the roots of the anterior teeth. Knowledge of the exact location and quantitative parameters of the mandibular incisive canal has high practical value. The implant detection of the aforementioned structure reduces the risk of anatomical and functional complications of surgical procedures in the mental area, including dental implant, bone harvesting and screwed plating of mandibular fractures [11]-[13].

During surgical procedures in the mandible, the mental interforaminal region is generally considered "a safe region" with minimal morbidity, however, it may present important risks for anatomical and functional damage. The presence of MIC is of significant interest, including the insertion of endosseous implants, the collection of bone from the mental bulge. However, the presence of MIC cannot be underestimated during pre-surgical planning and may cause sensory postoperative disturbances, edema, hematoma, and lack of implant bone integration [14].

The lower incisor canal is the medial extension of the mentual nerve, which is performed in the anterior region of the mandible and can open lingually near the mentual tubercle. The nerve may have varied course, with multimorphic representation. The number of cases with surgical intervention in the interforamal area has increased considerably since this region has good quality and bone quantity along with the perception that this is a safe zone. Failure to determine the exact position of the neurovascular bundle in this region may lead to complications such as transient or long-term paraesthesia of the associated region [15].

Detailed preoperative study of anatomical structures with cone-beam computed tomography is crucial for the success 
of the procedure and to reduce the number of postoperative complications after procedures in the area of the synphysis. Several studies have shown that, due to its excellent anatomical resolution, this test is the best method for obtaining incisor canal and for preoperative measurements, due to its reproducibility and high degree of reliability, results similar to anatomical studies in dry skull have been obtained [16], [17].

Thus, the present study will aim to collaborate with surgical planning by means of cone-beam computed tomography by evaluating the shape and metric of the mandibular incisor canal correlating with different facial growth patterns.

\section{MATERIALS AND METHODS}

The retrospective observational study was submitted and approved by the Ethics and Research Committee of the Federal University of Paraíba, João pessoa/PB, under the protocol CAAE 01617318.0.0000.5374.

\section{A. Sample determination}

In a total of 258 exams observed, from January 2015 to May 2019, 90 CBCT tests of extended face were selected after the facial growth patterns were determined and the exclusion criteria were applied: patients with bone malformation; with the presence of lesions in the region; history of trauma or previous surgical procedure; presence of impacted teeth and images with unsatisfactory quality for visualization of the region of the mental forame. This sample size of 90 participants provided test power of $0.80(\beta=0.20)$, for significance level of $0.05(\alpha=0.05)$ and effect size $w=0.39$, using the Gpower program.

The sample consisted of examinations of patients over 18 years of age and of both sexes and divided into three groups according to facial growth pattern: brachyfacials $(n=30)$; mesofacials $(n=30)$ and Dolicofacials $(n=30)$. Subsequently, the CBCT images were evaluated in order to perform morphometric analysis of the mandibular incisor canal.

All images observed were acquired with the same protocol using the i-CAT tomography (Imaging Sciences International, Hatfield, PA): 12-bit gray scale, voxel size of $0.25 \mathrm{~mm}$, FOV $13 \mathrm{X} 22 \mathrm{~cm}$. As standardization of tomographic evaluations, the images were analyzed by two previously calibrated examiners. Interobserver reproducibility (IOR) in the classification of facial growth patterns and morphometric analysis of the mandibular insive canal was evaluated by intraclass correlation coefficient (ICC) and Kappa, respectively. The IOR was excellent both linearly (ICC>0.9, p<0.0001) and nominally (kappa $=1.0$ ). They were obtained at two different times, when the facial growth pattern and morphometric analysis of the mandibular incisor canal were determined.

\section{B. Determination of facial growth patterns}

To determine the facial growth pattern, the VERT index of Ricketts cephalometric analysis was used. The cephalometric points of this analysis were obtained using the Dolphin ${ }^{\circledR}$ Imaging (Dophin Imaging System, USA) version 11.0. Cephalometric points requested by the analysis were marked to obtain the cephalometric tracing. The software illustrates all the points and sequence to tract them, offering the possibility of approximate visualization of the area in question without overlap of structures. From the union of the points, the digital tracings and the linear and angular values were obtained, automatically informed. In the final analysis the facial pattern is determined.

\section{Mic extension analysis}

All images were processed and worked on on Demand $3 \mathrm{~d} \AA$ (Cybermed, Seoul, Republic of Korea). These procedures were performed according to the protocol described above by Barbosa et al. 2020 [17] as shown in Fig. 1.

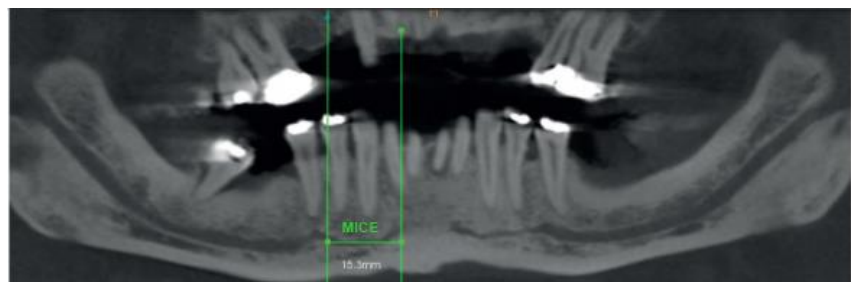

Fig. 1. Measurement of the extent of the mandibular incisive canal. Source: modified by [17]

In view of the panoramic tomographic reconstruction, the morphology of the canal was evaluated according to the review by Greenstein and Tarnow [18] (Fig. 2).

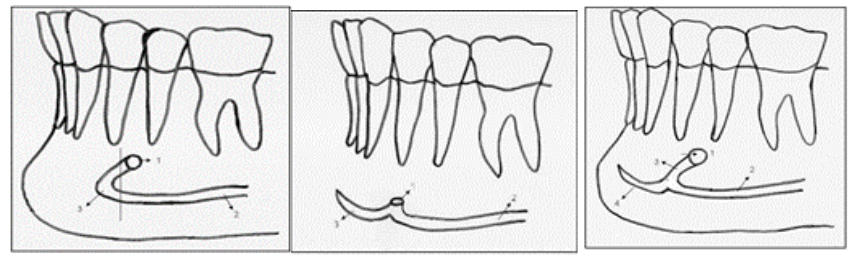

Fig. 2. Morphological evaluation of the mentual region Source: Greenstein and Tarnow Modified (2006).

\section{Statistical Analysis}

The data were tabulated in Excel and analyzed in SPSS v.20 (IBM Statistics) in order to verify the normality of data distribution using the Kolmogorov Sminorv test. Due to the abnormality in the distribution of numerical data related to the extension of the mandibular incisive canal (right side, left side and mean between canals) the Kruskal-Wallis test was used to test the interference of facial patterns, gender and age in the dependent variable. In the post-hoc analysis, the Mann Whitney test was used to determine in which groups there was a statistically significant difference with the measurements of incisive canal extensions. The Friedman test was used in the intragroup analysis of the dependent variable. The chi-square independence test was used to verify differences between categorical variables. A confidence interval of $95 \%$ and a significance level of 5\% were considered.

\section{RESULTS}

Conical beam computed tomography scans were analyzed in 90 individuals, divided into three groups containing 30 of each facial pattern, in order to obtain the relationship of the extent, shape and location of the incisive canal (Table 1). 


\begin{tabular}{|c|c|c|c|}
\hline & & $\mathrm{N}$ & $\%$ \\
\hline \multirow{3}{*}{ Sex } & Male & 49 & 54,4 \\
\hline & Female & 41 & 45,6 \\
\hline & Total & 90 & 100 \\
\hline \multirow{3}{*}{ Age } & $<30$ & 88 & 97,8 \\
\hline & $>30$ & 2 & 2,2 \\
\hline & Total & 90 & 100 \\
\hline
\end{tabular}

\section{A. Facial Pattern Analysis on Incisive Channel Extension}

The kruskal-wallis test showed that there is effect of the facial pattern on the right extension $[X 2(2)=16.217 ; \mathrm{p}<0.001]$ and left of the incisive canal [X2(2)=19.823; $<<0.001]$, and on the average between the sides $[\mathrm{X} 2(2)=25,384 ; \mathrm{p}<0.001]$.

In análise the post-hoc analysis, comparison was performed using the Mann-Whitney test, which showed statistically significant difference between dolichofacials and mesofacials individuals for both REIC $(U=231 ; p=0.240)$, LEIC ( $U=225$; $p=0.445)$ and for LEIC $(U=159 ; p=0.124)$. However, brachyfacials individuals diverged both from mesofacial individuals $[\mathrm{REIC}=(\mathrm{U}=112 ; \mathrm{p}=0.001)$; LEIC $(\mathrm{U}=106 ; \quad \mathrm{p}=0.001) ; \quad$ LRIC $\quad(\mathrm{U}=41 ; \mathrm{p}<0.001)], \quad$ for dolichofacials individuals [REIC $(\mathrm{U}=105 ; \mathrm{p}<0.001)$, LEIC $(\mathrm{U}=116 ; \mathrm{p}<0.001)$ and for LRIC $(\mathrm{U}=51 ; \mathrm{p}<0.001)]$ in all measurements performed in the present study (Table 2 ).

In the intragroup analysis performed using the Friedman test, no difference was observed between the incisive canal length in REIC, LEIC and LRIC [X2(2)=1; p=0.607] (Table 2).

The median size of the mandibular incisor canal in the dolicofacial group was $4.24 \mathrm{~mm}$ in REIC, $4.25 \mathrm{~mm}$ in LEIC and $4.10 \mathrm{~mm}$ in LRCI (Fig. 3). In mesofacial individuals, the values were $5.30 \mathrm{~mm}$ in REIC $5.27 \mathrm{~mm}$ in LEIC and $5.55 \mathrm{~mm}$ in LRCI (Fig. 4). Considering brachyfacial individuals, the median extensions were $10.32 \mathrm{~mm}$ in REIC, $10.63 \mathrm{~mm}$ in LEIC and 11.09mm in LRCI (Fig. 5).

TABLE 2: NUMBER OF PARTICIPANTS, MEDIANS AND INTERQUARTILE DISTANCE OF INCISIVE CANAL EXTENSION IN DIFFERENT FACIAL PATTERNS

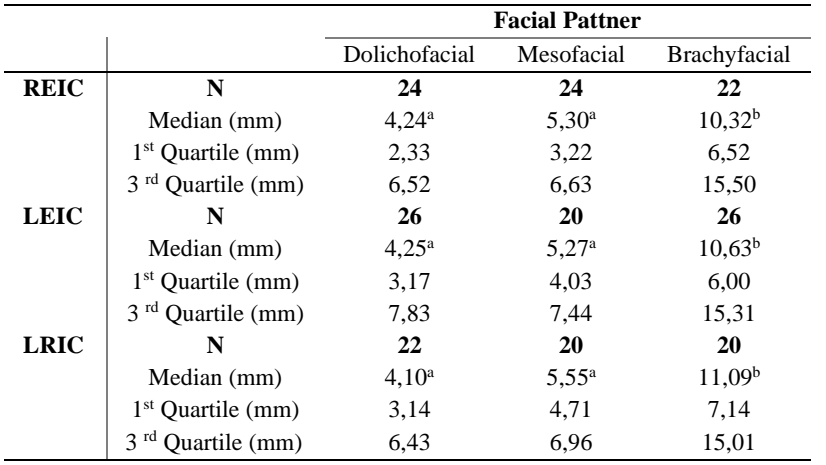

REIC*: Right Extension of the Incisive Canal.

LEIC*: Left Extension of the Incisive Canal.

LRIC*: Average between the left and right side of the Incisive Canal.

Different lowercase letters represent statistical differences between facial patterns $(\mathrm{p}<0.05)$.

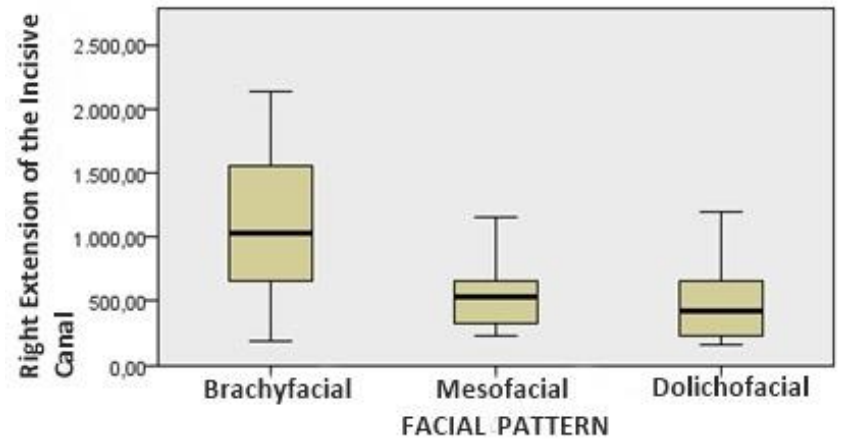

Fig. 3. Distribution of data by facial pattern in the right extension of the mandibular incisor canal.

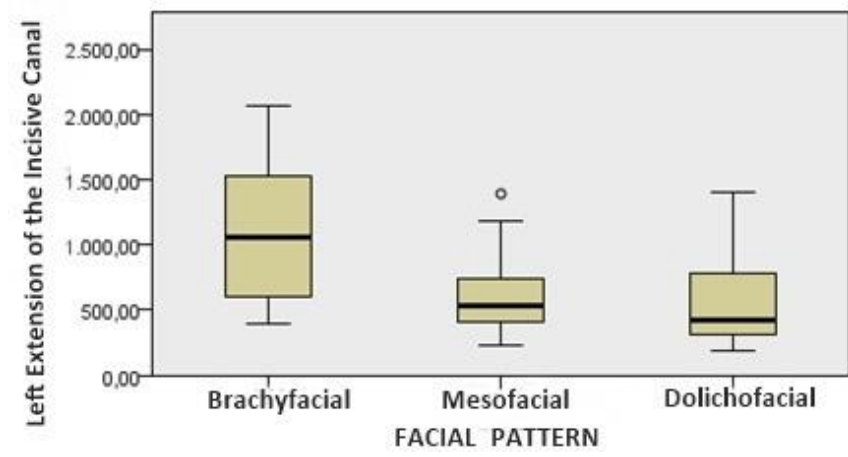

Fig. 4. Distribution of data by facial pattern in the left extension of the mandibular incisor canal.

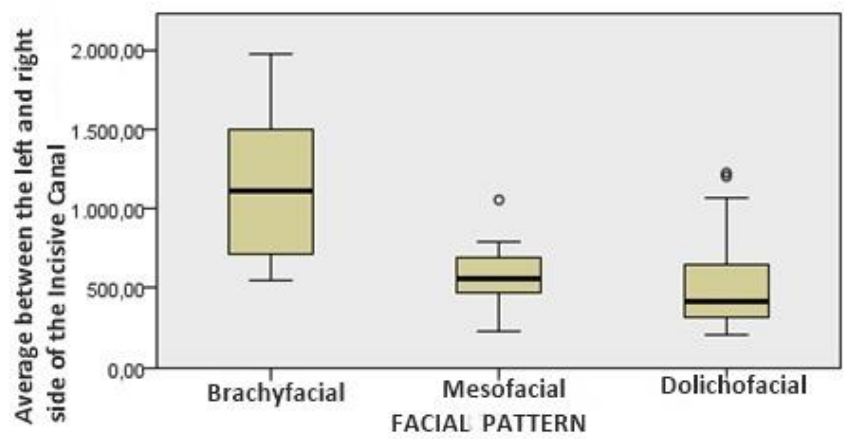

Fig. 5. Distribution of data by facial pattern in the mean values of the left and right extensions of the mandibular incisor canal.

\section{B. Analysis of the Influence of Sex On the Extension of the Incisive Channel}

In the analysis, comparing the relationship between sex and the extension of the mandibular incisor canal using the MannWhitney test, it showed no statistically significant difference between males and females for both REIC $(U=597 ; p=0.897)$, LEIC (U=504; $\mathrm{p}=0.109)$ and for LRIC $(\mathrm{U}=442 ; \mathrm{p}=0.607)$. (Table 3).

TABLE 3: RELATIONSHIP BETWEEN THE SEX OF THE INDIVIDUALS AND THE LENGTH OF THE MANDIBULAR INCISOR CANAL.

\begin{tabular}{|c|c|c|c|c|c|}
\hline & SEX & $\mathbf{N}$ & $\begin{array}{c}\text { Ranked } \\
\text { Average }\end{array}$ & $\mathbf{U}$ & P-VALUE \\
\hline \multirow{2}{*}{ REIC } & Male & 38 & 35,79 & & \\
\hline & Female & 32 & 35,16 & 597 & 0,897 \\
\hline \multirow{2}{*}{ LEIC } & Male & 38 & 32,76 & & \\
\hline & Female & 34 & 40,68 & 504 & 0,109 \\
\hline \multirow{2}{*}{ LRIC } & Male & 33 & 30,39 & & \\
\hline & Female & 29 & 32,76 & 442 & 0,607 \\
\hline
\end{tabular}

REIC*: Right Extension of the Incisive Channel.

LEIC*: Left Extension of the Incisive Channel.

LRIC*: Average between the left and right side of the Incisive Channel. 


\section{Analysis of the Influence of age on incisive channel extension}

In the analysis, comparing the relationship between age and extension of the mandibular incisor canal using the Mann-Whitney test, it showed no statistically significant difference between individuals aged 30 years or less, both for REIC ( $U=12 ; p=0.371)$, LEIC $(U=29 ; p=0.188)$ and for LRCI $(U=16 ; p=0.548)$ - (Table 2). This absence of difference between age and extension of the mandibular incisor canal may be related to $n$ in the group older than 30 years of age being lower than that of individuals under 30 years of age, due to convenience sampling. The chi-square adherence test showed that the data obtained are inconsistent with the expected distribution $[\mathrm{X} 2(1)=82.17 ; \mathrm{p}<0.001]$ as observed in Table 4.

TABLE 4: RELATIONSHIP BETWEEN THE RANKING OF THE AGE OF THE INDIVIDUALS AND THE LENGTH OF THE MANDIBULAR INCISOR CANAL

\begin{tabular}{c|c|c|c|c|c}
\multicolumn{2}{c}{ INDIVIDUALS AND THE LENGTH OF THE MANDIBULAR INCISOR CANAL } \\
\hline \multirow{2}{*}{ REIC } & Age & $\mathbf{N}$ & $\begin{array}{c}\text { Ranked } \\
\text { Average }\end{array}$ & U & P-value \\
\hline \multirow{2}{*}{ LEIC } & $>30$ & 69 & 35,83 & & \\
& $>30$ & 1 & 13,00 & 12 & 0,371 \\
\hline \multirow{2}{*}{ LRIC } & $<30$ & 61 & 30,26 & & \\
& $>30$ & 1 & 46,00 & 16 & 0,188 \\
\hline
\end{tabular}

REIC*: Right Extension of the Incisive Channel

LEIC*: Left Extension of the Incisive Channel

LRIC*: Average between the left and right side of the Incisive Channel

\section{Mandibular Incisive Canal Morphology Analysis and Facial Pattern}

Observing the morphology data of the mandibular incisive canal and relating them to facial patterns, we can see that the horizontal linear shape $(\mathrm{C})$ was more prevalent in the three facial patterns, totaling the morphology of $57.8 \%$ of the studied sample (Table 5).

A chi-square test of independence was performed to evaluate the difference between the morphologies of the incisive canal and facial patterns and we found that there is no association between the facial pattern and the morphologies of the mandibular incisive canal $[\mathrm{X} 2(10)=$ $3.365 ; \mathrm{p}=0.971]$.

\section{DISCUSSION}

In the present study we observed that the pattern of facial growth significantly influenced the extension of the mandibualar incisive canal, and brachyfacials were the ones that appeared greater extension. These results are in accordance with the literature showing that several structures of the maxillofacial complex have their morphology altered according to the facial growth pattern of individuals [19], [20].

In the study by [20] the extension of the mandibular incisive canal was evaluated bilaterally in 150 individuals. The length of the canal found was $13.4 \mathrm{~mm}$ (range from 5.6 to $24.7 \mathrm{~mm}$ ) on the right side and $12.4 \mathrm{~mm}$ (range from 4 to $22.5 \mathrm{~mm}$ ) on the left side, these results are in line with the results established in this study.

The extent of the mandibular incisive canal was established as being the distance from the mental forame towards the roots of the anterior teeth at the level of which the canal can no longer be visualized. Nowadays, many surgeries are performed on the anterior part of the jaw, including dental implants, orthognathic surgeries, removal of grafts among others. The anterior area of the mandibular bone is assumed to be safe for these procedures. The problem is the presence of the mandibular incisive canal which has been shown to have a high frequency of presence [20]-[23].

Regarding gender, the bilateral analyses of the incisor channels concluded that, even if there was a difference between the samples, no important relevance was found for the study. Second [16] in a study to detect the mandibular incisive canal, 50 images of cone-beam computed tomography were analyzed, 25 males and 25 females, and when compared only to gender, the result was also irrelevant.

In the study by Lim \& collaborators [18] a total of 100 CBCT images were analyzed, all of which identified the MIC. Subsequently, the analyses were advanced by dividing the groups into three age groups (18-38, 39-59, 60-80) in which, after being examined, they did not obtain statistically important variation in relation to the age of the samples.

TABLE 5: TYPE OF MORPHOLOGY, LOCATION OF MORPHOLOGY ACCORDING TO EACH FACIAL PATTERN

\begin{tabular}{|c|c|c|c|c|c|c|c|c|}
\hline & & \multicolumn{2}{|c|}{$\mathbf{A}$} & \multicolumn{2}{|c|}{$\mathbf{B}$} & \multicolumn{2}{|c|}{$\mathbf{C}$} & \multirow{2}{*}{ TOTAL } \\
\hline & & $\mathrm{R}$ & $\mathrm{L}$ & $\mathrm{R}$ & $\mathrm{L}$ & $\mathrm{R}$ & $\mathrm{L}$ & \\
\hline \multirow{3}{*}{ DOLICHOFACIAL } & $\mathrm{N}$ & 8 & 6 & 7 & 5 & 14 & 20 & 60 \\
\hline & $\%$ in facial pattner & 13,3 & 10 & 11,7 & 8,3 & 23,3 & 33,3 & 100 \\
\hline & $\%$ in morphology & 4,4 & 3,3 & 3,9 & 2,8 & 7,8 & 11,1 & 31,7 \\
\hline \multirow{4}{*}{$\begin{array}{c}\text { MESO } \\
\text { FACIAL }\end{array}$} & $\mathrm{N}$ & 6 & 5 & 6 & 9 & 17 & 17 & 60 \\
\hline & $\%$ in facial pattner & 10 & 8,3 & 10 & 15 & 28,3 & 28,3 & 100 \\
\hline & $\%$ in morphology & 3,3 & 2,8 & 3,3 & 5 & 9,4 & 9,4 & 36,5 \\
\hline & $\mathrm{N}$ & 9 & 5 & 5 & 5 & 16 & 20 & 60 \\
\hline \multirow[t]{2}{*}{ BRACHYFACIAL } & $\%$ in facial pattner & 15 & 8,3 & 8,3 & 8,3 & 26,7 & 33,3 & 100 \\
\hline & $\%$ in morphology & 5 & 2,8 & 2,8 & 2,8 & 8,9 & 11,1 & 36,5 \\
\hline \multirow{3}{*}{ TOTAL } & $\mathrm{N}$ & 23 & & 18 & 19 & 47 & 66 & 180 \\
\hline & $\%$ in facial pattner & 12,8 & 16 & 10 & 10 , & 26,1 & 31,7 & 100 \\
\hline & $\%$ in morphology & 21,7 & 8,9 & 20,6 & 6 & 57,8 & & 100 \\
\hline
\end{tabular}

A*:MIC in loop.

$\mathrm{B} *$ :MIC Undisplayed.

$\mathrm{C}: \mathrm{MIC}$ linear horizontal.

$\mathrm{R}^{*}: \mathrm{MIC}$ on the right side.

$\mathrm{L}: *$ MIC on the left side. 
In a study by Barbosa \& collaborators [17] the MIC presented an average length of $7.7 \mathrm{~mm}$ and different vertical and horizontal diameters in the initial and final parts. In addition, both the distance between mic and lingual cortical of the mandibular alveolar bone and the diameter of mic decreased as its trajectory took a more anterior position.

According to a study by Zhang \& collaborators [24] after analysis of 535 images, oscillation was verified in relation to the length of the MIC that was from $6.6 \mathrm{~mm}$ to $40.3 \mathrm{~mm}$. Large variations in the data in relation to the present study and previous research can be explained by differences in ethnic origin, sample size, image resolution and specifications of anatomical structures.

Morphometric analysis showed that data such as length, width and distances from MIC to dental elements and the lower limit of the mandible are frequently evaluated parameters, due to the fact that this knowledge is clinically interesting to perform treatments in the mandibular intermental area. However, we did not find substantial agreement between the values described in the literature, presenting a high variation of values even when the same technique was used, suggesting that it is still necessary to better define these morphometric parameters [25]-[27].

According to Adamiec et al. [28] the incisive canal of the jaw has its variable morphology, and its symmetry is nonexistent. In the present study, the authors highlight the variation, mainly, in relation to the diameter of the canal that ranges from $0.35 \mathrm{~mm}$ to $4.12 \mathrm{~mm}$. Regarding the path and the way the structure moves in the mandible, a horizontal linear predominance with apical linear destination to the previous dental elements was observed in the analyzed figures, reproducing the data from the current research.

According to Vázquez \& collaborators [29] a study conducted with 100 tomographic images involving toothless and toothless patients, divergences were found in relation to the average diameter of the mandibular incisor canal. In toothed patients, the average result was $1.42 \mathrm{~mm}$ and in the toothless $1.16 \mathrm{~mm}$, which concludes that the second group presents a flattened form, accompanied by mandible atrophy.

Therefore, we can conclude that brachyfacials, when compared to the bilateral median extension of the mandibular incisive canal, stand out for presenting longer $(11.09 \mathrm{~mm})$ and with a statistically significant difference compared to the mesofacial group $(5.55 \mathrm{~mm})$ and with the dolichofacial group $(4.10 \mathrm{~mm})$. There was no relevant difference when compared bilaterally the mandibular incisive canal in relation to age, sex and morphology.

\section{REFERENCES}

[1] Abesi, F, Nikafshar N, Haghanifar S, Khafri, s., Hamzeh, m. Can the Inversion Filter Improve the Visibility of the Mandibular Incisive Canal? Irã J Radiol, p. 01, 2016. Jan; 13(1): e22698.

[2] Beltran V, Cantín M, Fernández RF, Engelke W. Bilateral Presence of the Incisive Jaw Channel. An Anatomical Structure with Clinical Estructura Relevancia Relevance. International Journal of Morphology, v. 29, n. 2, p. 543, 2011

[3] Benedicto, E. N., Kairalla, S. A., Kaieda, A. K., Miranda,S. L., Torres,F. C., Paranhos, L. R. Determination of the vertical skeletal pattern of the face. Rev Bras Cir Craniomaxilofac, p. 45, 2011.

[4] Berwig, L.C., Ritzel, R. A., Silva,A. M. T., Mezzomo C. L., Côrrea E. C. R., Serpa,E. O. Habitual position of crescimento the tongue and lips in the anteroposterior and vertical growth patterns. CEFAC Magazine, v. 107, p. 108, 2015.

[5] Bottacin F. S, Stuani M. B., Taba M. Jr. Modification in microbiota and evaluation by cone beam computed tomography during orthodontic treatment. Journal of Dental Science, Oral and Maxillofacial Research v. 1 , ed. 02 , p. $01,2018$.

[6] Câmara ,A. O., Rodrigues, G. M. F., Lima, K. J. R. S., Beltrão,R. V., Beltrão, R. T. S. Correlation between Padrões Facial Growth Patterns and Third Molars Included. Revista Brasileira de Ciências da Saúde,v. 21, n. 3, p. 240, 2017.

[7] Carvalho, A. A. B. C., Corrêa, L. A. A. F., Freitas,F. F., Dias,P. C. Importance of conical beam computed tomography in the evaluation of canine included in the maxilla. Revista Brasileira de Odontologia,v. 74 n. 02, p. 144 and 147, 2017.

[8] Chiapasco, M., DI Martino, G., Anello, T., Zaniboni, M., Romeo, E. Fresh frozen versus autogenous iliac bone for the rehabilitation of the extremely atrophic .maxilla with onlay grafts and endosseous inplants: preliminary results of a prospective comparative study. Clin Implant Dent, 2015.

[9] Choi, D. J., Kim, K. D., Jung, B. Y. The location of the mandibular incisive canal related to the placement of dental implants: A case report. Journal of Oral Implantology, n. 6, p. 4, 2018.

[10] Floriani, M. R., Meirelles, M. P. M. R., Sousa,M. L. R. Use of acupuncture in a case of paresthesia of the lower alveolar and lingual nerves. caso Journal of the São Paulo Association of Dentists , v. 66, n. 4, p. 313, 2012.

[11] Franco, F. C. M., Araujo, T. M., Vogel, C. J., Quintão, C. C. A. Brachycephalic, dolichocephalic and mesocephalic: Is it appropriate to describe the face using skull patterns? Dental Press Journal of Orthodontics, p. 161, 2013

[12] Fuentes R., Arias, A., Bucchil, C., Saravia, D., Dias, F. Prevalence and Morphometric Characteristics of the Mandibular Incisive Canal through Panoramic Radiographs in a Chilean Population. International Journal of Morphology, v. 35, n. 3, p. 931 e 937, 2017.

[13] Jawad Z., Carmichael F., Houghton N., Bates C. A review of cone beam computed tomography for thediagnosis of root resorption associated with impacted canines, introducing an innovative root resorption scale. Oral Surg Oral Med Oral Pathol Oral Radiol, p. 02, 2016.

[14] Jensen O. T. Segmental Alveolar Split Combined With Dental Extractions and Osteotome sinus floor intrusion in posterior maxilla using BMP-2\ACS Allograft for alveolar reconstruction: technical note and report of three cases. J Oral Maxillofac Surg, p. 2043, 2013.

[15] Kabak S. L., Zhuravleva N. V., Melnichenko Y. M. Study of the mandibular incisive canal anatomy using cone beam computed tomography. Surg Radiol Anat. Springer-Verlag France, p. 123-124, 2016.

[16] Kong, N., Hui, M., Miao, F., Yuan, H., Du, Y., Chen, N. Mandibular incisive canal in Han Chinese using cone beam computed tomography. Int J Oral Maxillofac, p. 02, 2016.

[17] Barbosa, D. A. F., Kurita, L. M., Pimenta, A. V. M., Teixeira, R. C., Silva, P. G. B., Ribeiro, T. R., Melo, D. P., Costa, F. W. G. Mandibular incisive canal-related prevalence, morphometric parameters, and implant placement implications: a multicenter study of 847 CBCT scans. Med Oral Patol Oral Cir Bucal, 2020.

[18] Greenstein, G., Tarnow, D. The Mental Foramen and Nerve: Clinical and Anatomical Factors Related to Dental Implant Placement: A Literature Review. Journal of Periodontology, 77, p.1933-1943. 2006.

[19] Maciel, P. P, Sousa, E. T, Sales, M. A. O. The mandibular incisive canal and its anatomical relationships: A cone beam computed tomography study. Journal section: Oral Surgery, p. 724, 2015.

[20] Malasure, P. C., Navalkar, A., Das D., Patil, B. Assessing the Dimensions of Mandibular Incisive Canal and its Relationship to Adjacent Anatomical Landmarks Using Cone Beam Computed Tomography in Indian Sub-Population - A Retrospective Study. Department of Oral Medicine and Radiology, v. 31, ed. 2, 2019.

[21] Oliveira, R. S. , Oliveira, A. M. G., Junqueira J. L. C. , Panzarella, F. K. Association between the Anatomy of the Mandibular Canal and Facial Types: A Cone-Beam Computed Tomography Analysis, International Journal of Dentistry, vol. 2018, Article ID 5481383, 9 pages, 2018.

[22] Orhan K., Aksoy S., Bilecenoglu B. Evaluation of bifid mandibular canals with cone-beam computed tomographyin a Turkish adult population. Oral MaxillofacSurg. p. 501-507, 2011.

[23] Panjnoush M., Kheirandish Y., Zeini N. Effect of Spatial Position in the Field of View on Dimensional Changes in Cone Beam Computed Tomography. Journal of Dentistry, Tehran University of Medical Sciences, v. 14, n. 5, p. $282-283,2017$. 
[24] Zhang, Y. Q., Yan, X. B., Zhang, L. Q., Xie, X. Y., Liu, D. G., Zhang, Z. Y. Prevalence and Morphology of Mandibular Incisive Canal: Comparison among Healthy, Periodontitis and Edentulous Mandibles In a Population of the Beijing Area Using Conebeam Computed Tomography. Chinese Journal of Dental Research, 2019.

[25] Pires, C. A., Bissada, N. F., Becker, J. J., Kanawati, A., Landers, M. A. Mandibular Incisive Canal: Cone Beam Computed Tomography. Clinical Implant Dentistry and Related Research, v. 14, n. 1, p. 68 e 71, 2012.

[26] Prates, L. S., Gois,L., Berwig,L. C., Dutra,A. P. B., Stella,A. R. B., Silva,A. M. T. Clinical and crescimento electromyographic evaluation of chewing in different facial growth patterns. MAGAZINE CEFAC, v. 18, n. 1, p. 105, 2016.

[27] Ramesh A. S, Rijesh K., Sharma A., Prakash R., Arun K., Karthik. The prevalence of mandibular incisive nerve canal and to evaluate its average location and dimension in Indian population. Journal of Pharmacy and Bioallied Sciences, p. 02, 2015.

[28] Adamiec, M., Michalska, A., Wesolowski, P., Perek, J. N., Nieckula, P., Wojtowicz, A. Assessment of the incidence and dimensions of the mandibu canal - aspects in the planning of implant treatment. Dent. Med. Probl., 2015.

[29] Vazquez, D., Estevez, A., Pujol, M., et al. Study of anatomical variants in the incisive duct in toothless patients using conical beam tomography. ADM Magazine, 2019.

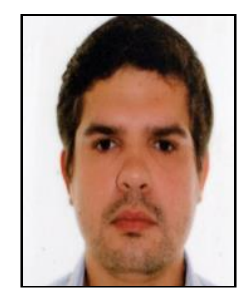

Rudyard dos Santos Oliveira

Phd in Orthodontics - São Leopoldo Mandic college - Campinas/SP.

Msc in Oral Radiology - São Leopoldo Mandic college- Campinas/SP.

Specialist in orthodontics, implantology, stomatology and public health. 